CONTEMPORARY

ISSUES IN

NEUROLOGIC

PRACTICE

AMERICAN ACADEMY OF

NEUROLOGY.

\section{American Academy of Neurology policy on pharmaceutical and device industry support}

J.C. Hutchins, JD

C.M. Rydell, CAE

R.C. Griggs, MD, FAAN

M. Sagsveen, JD

J.L. Bernat, MD, FAAN

For the American

Academy of

Neurology

Pharmaceutical and

Device Industry

Conflict of Interest

Task Force

Correspondence \& reprint requests to $\mathrm{Mr}$. Hutchins: jhutchins@AAN.com
Supplemental data at www.neurology.org



Podcast

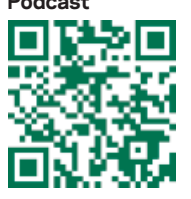

\section{ABSTRACT}

Objective: To examine the American Academy of Neurology (AAN)'s prevention and limitation of conflicts of interest (COI) related to relationships with pharmaceutical and medical device manufacturers and other medically related commercial product and service companies (industry).

Methods: We reviewed the AAN's polices governing its interactions with industry, mechanisms for enforcement, and the recent findings of the board-appointed COI task force, in the context of the 2009 David Rothman and colleagues' article in JAMA, the Council of Medical Specialty Societies (CMSS) Code for Interactions with Companies (Code), efforts of the American Medical Association in this area, and increased public and Congressional scrutiny of physician/physician organizations' relationships with industry.

Results: The AAN's Policy on Conflicts of Interest provides 4 mechanisms for addressing COI: avoidance, separation, disclosure, and regulation. The AAN's Principles Governing Academy Relationships with External Sources of Support, including recent amendments proposed by the COI task force, regulate industry interaction with AAN programming, products, and leadership. With the Policy, Principles, and other methods of COI prevention, the AAN meets or exceeds all recommendations of the CMSS Code.

Conclusions: With its adherence to the Principles since 2004, the AAN has been a leader among professional medical associations in appropriately managing $\mathrm{COI}$ related to interactions with industry. Recent amendments to the Principles maintain the AAN's position as a leader in a time of increased public scrutiny of physicians' and professional medical associations' relationships with industry. The AAN is responsive to the recommendations of the COI task force, and has adopted the CMSS Code. Neurology ${ }^{\circledR}$ 2012;78:750-754

\section{GLOSSARY}

AAN = American Academy of Neurology; CEJA = Council on Ethical and Judicial Affairs; CMSS = Council of Medical Specialty Societies; $\mathbf{C O I}=$ conflicts of interest; $\mathbf{P M A}=$ professional medical association

The American Academy of Neurology and its affiliated organizations (AAN) have relationships with industry, including pharmaceutical and medical device manufacturers and other medically related commercial product and service companies, which have mutual benefits, but carry the risk of conflicts of interest (COI). COI may cause unintended harm by creating bias, favoritism, undue influence, and a resulting loss of public and member confidence in the integrity and objectivity of the AAN. In recognition of these risks, the AAN has longstanding policies to prevent and limit $\mathrm{COI}$ and their consequences, including strict enforcement mechanisms to guarantee that the policies are followed.

In this article, we highlight the response of the AAN to the heightened concern about industry COI through an AAN Board of Directors-appointed task force, a review of existing policies, and the implementation of newly revised policies governing AAN relationships with industry. We also note what we consider important issues regarding COI and biases that have not yet been appropriately addressed.

PROMOTING AND PROTECTING THE AAN'S MISSION The AAN's vision is to be indispensable to its members. This goal is accomplished by promoting the highest quality patient-centered neurologic care and

From the American Academy of Neurology (J.C.H., C.M.R., M.S.), St. Paul, MN; Department of Neurology (R.C.G.), University of Rochester, NY; and Dartmouth-Hitchcock Medical Center (J.L.B.), Lebanon, NH.

Disclosure: Author disclosures are provided at the end of the article. 
enhancing member career satisfaction through providing education, information, policy development, and advocacy for AAN members and patients; by setting and maintaining the highest ethical and professional standards for members, staff, and programs; and by upholding the integrity of the AAN and keeping the interests of patients first.

The interests of industry are to produce, market, and sell medical products and services that provide benefits to customers and yield profits for industrialists and shareholders. Pharmaceutical and medical equipment manufacturers strive to benefit patients by providing products and services that help physicians diagnose, treat, and rehabilitate patients. To carry out the $\mathrm{AAN}^{\prime}$ s mission, its members prescribe industry-developed treatments that their patients need and use. Therefore, relationships between the AAN and industry are natural and mutually beneficial.

The principal risk in AAN-industry relationships is the development of COI that jeopardize $\mathrm{AAN}^{\prime} \mathrm{s}$ mission. COI are situations in which professional judgment concerning a primary interest such as patient welfare is unduly influenced by a secondary interest such as financial gain. COI are a serious problem for physicians if they demote the primacy of the patient's interests and if their presence diminishes the overall confidence that patients and the public have in the medical profession. For medical societies such as the AAN, COI could diminish the confidence of AAN members, patients, and the public in the AAN's integrity and could jeopardize the AAN's core value to keep the interests of patients first.

Relationships with industry can produce COI or the appearance of COI, if AAN members, patients, or the public believe that the AAN has sacrificed its credibility and integrity by promoting the interests of industry for its financial gain. The use of industry support to offset costs of AAN programs and offerings makes the issue of maintaining our organizational independence, credibility, and integrity a serious ongoing concern. This concern is magnified by the national publicity generated by current inquiries by the United States Congress into relationships between physicians and industry, and between medical associations and industry, in which all relationships are suspect, scrutinized, and publicized. This trend of increasing public scrutiny makes even the appearance of COI a liability for the AAN.

AN ENVIRONMENT OF INCREASED SCRUTINY OF MEDICAL ASSOCIATION-INDUSTRY RELATIONSHIPS In 2009, David Rothman and colleagues ${ }^{1}$ published a prominent but controversial article discussing support of professional medical associations (PMAs) by monies from the pharmaceutical and medical device industries. The position pa- per was developed by the PMA Task Force, whose members included former PMA presidents, the editor of JAMA, 4 current and former CEOs of PMAs, as well as others. The AAN Executive Director (Catherine Rydell) was one of the PMA CEOs. She had AAN board approval to participate and had an advisory group of AAN leaders she consulted during the year-long process. While all PMA Task Force members represented themselves and not their affiliated societies, they were apparently chosen for the Task Force because of their affiliations and experience with PMAs and industry support. Several of Ms. Rydell's recommendations were included in the document but ultimately she and the AAN Board did not agree with certain aspects of the report (discussed below). As a result she, with AAN Board support, withdrew her name from the final report.

Historically, physicians, medical societies, and others have attempted to regulate COI with varied success. Whether the scrutiny is internal by physician-led organizations such as the AMA and Council of Medical Specialty Societies (CMSS), by external entities such as the US Congress, or by watchdogs of the medical profession such as Rothman, the issue is the same: how do physicians and their professional societies reduce or eliminate the real or perceived COI with industry?

The CMSS is an organization of 38 national medical specialty societies with an aggregate membership of 700,000 US physicians. In the spring of 2009, the CMSS Board of Directors appointed a task force comprised of representatives of CMSS member PMAs charged with developing and recommending a code of conduct for PMAs to "enhance professionalism and to disclose, manage, and resolve relationships with industry." 2 The AAN belongs to CMSS and AAN representatives served on the task force. The Code for Interactions with Companies was adopted by CMSS on April 17, 2010, with a revised version adopted on March 19, 2011. ${ }^{2}$ The Code is a set of guiding principles whose key features include disclosure, independent society leadership, independent program development, and elimination and management of COI. To date, 37 medical societies — including the AAN- have formally signed the Code. ${ }^{3}$

AAN RESPONDS; APPOINTMENT OF AN AAN-INDUSTRY COI TASK FORCE The AAN

Board of Directors and the AAN Ethics, Law and Humanities Committee previously established policies addressing AAN relationships with industry and COI: the Principles Governing AAN Relationships with External Sources of Support, first published in $2004,{ }^{4}$ and the Policy on Conflicts of Interest, substantially amended in $2008.5^{5}$ In response to the article by 
Rothman et al. ${ }^{1}$ and the contemporaneous COI policy formulation by the CMSS, ${ }^{2}$ AAN leadership commissioned an ad hoc task force in 2009 to 1) evaluate the extent of AAN-industry relationships; 2) review existing AAN policies that regulate the relationships in the context of policies of other professional medical associations and prevailing ethical standards; and 3) make recommendations to limit COI in such relationships. The task force met in weekly conference calls over several months. They incorporated input from AAN members during the 2010 AAN Ethics Colloquium and comments from AAN leadership and the AAN Board of Directors. The task force made their recommendations from their findings in the form of proposed amendments to the Principles Governing AAN Relationships with External Sources of Support. The revised Principles document was approved by the AAN Board of Directors and adopted by the AAN Foundation Board of Trustees in June 2010 (e-supplement on the Neurology ${ }^{\circledR}$ Web site at www.neurology.org).

THE AAN TASK FORCE FINDINGS The task force found many of $\mathrm{AAN}^{\prime}$ s existing policies and practices to be proficient in appropriately preventing or managing COI related to AAN relationships with industry and consistent with prevailing codes and standards (including ACCME standards and aspects of the Rothman et al. article and the CMSS Code).

The AAN Policy on Conflicts of Interest provides 4 general strategies to remedy COI: avoidance, separation, disclosure, and regulation. ${ }^{5}$ Complete avoidance of relationships between the AAN and industry is not a reasonable strategy because areas of appropriate mutual gain would be sacrificed unnecessarily and because effective and less radical remedies are available. Separation from and avoidance of serious COI remain important strategies. Public disclosure of COI is an essential step but only mitigates the COI by making others aware of it. Regulation is a necessary strategy to promote mutual interests while minimizing the possibility of COI. Regulation requires the drafting of effective policies and their vigilant enforcement. The Principles Governing Academy Relationships with External Sources of Support is the AAN's primary policy in providing such regulation.

In 2004, the AAN Board of Directors approved the Principles Governing AAN Relationships with External Sources of Support, which outline 6 principles and 8 special guidelines to be observed when establishing and maintaining relationships with external sources of support, including industry supporters. ${ }^{4}$ While the task force concluded that historically these principles and guidelines have provided the AAN with the appropriate general oversight needed to pre- vent or manage COI with regards to industry, the task force recommended that a section be added to the Principles specifically outlining special guidelines concerning AAN relationships with industry. The task force proposed this section as a means to enhance AAN regulation of COI by providing AAN staff and member leadership with specific guidance on how the well-established principles and guidelines of 2004 apply in particular contexts involving industry (e.g., CME programming, advocacy training, guideline development and dissemination, exhibit hall activities). ${ }^{4}$

The task force identified several goals they felt would be met by their proposed amendments to the Principles. All AAN policies governing relationships with industry must be transparent to members and the public. These policies must assure that any financial support of the AAN by industry is not conditional on any real or implied quid pro quo. Industry monies or representation ought not to influence AAN administration, policies, services, practices, or educational activities. AAN policies should address the public relations issue of the appearance of COI or undue influence. Such influence grows in magnitude in proportion to the extent of AAN financial relationships with industry. AAN policies governing relationships with industry should be configured to allow appropriate areas of mutual benefit while, most importantly, maintaining the AAN's high ethical and professional standards and protecting its most valuable and cherished asset, its credibility and integrity as a PMA.

COMPARING AAN POLICY TO CMSS, ROTHMAN, AMA The task force considered, adapted, and incorporated arguments and recommendations from the CMSS Code for Interactions with Companies and from the article by Rothman and colleagues. With existing policies and practices, and the amendments to the Principles, AAN meets or exceeds the recommendations of the CMSS Code. For example, the AAN discloses the breakdown of industry contribution toward the consolidated revenue of the AAN and its affiliates on its Web site, ${ }^{6}$ as well as disclosure statements reported by each member of the AAN Board of Directors. ${ }^{7}$ The Key Society Leaders of the AAN as defined by the CMSS Code, i.e., officers at the presidential level of the society's membership organization (AAN), the CEO/Executive Director of the membership organization, and the Editor-inChief of the society's journal, are free of direct financial relationships with industry, i.e., "a relationship held by an individual that results in wages, consulting fees, honoraria, or other compensation ... for the individual's services or expertise." 2 
Rothman and colleagues identified several guiding principles to consider when addressing relationships with industry, which the AAN supports: transparency, diversification of support, and firewalls to prevent inappropriate influence on programs and publications. However, the AAN disagrees with some of Rothman and colleagues' recommended methods for enacting these principles. For example, Rothman et al. concluded with a "proposal for controlling PMA conflict of interest" that "PMAs should work toward a complete ban $(\$ 0)$ on pharmaceutical and medical device industry funding, except for income from journal advertising and exhibit hall fees." Recognizing the difficulty of immediately meeting this goal, they recommended PMAs begin by "restrict[ing] total support to no more than $25 \%$ of [the] operating budget." AAN, along with the CMSS Code signatories, believe a complete ban on funding stifles a mutually beneficial relationship between PMAs and industry in which the 2 groups share a common interest of supporting patient wellbeing and medical innovation, with an understanding that these relationships must be highly regulated. AAN and CMSS regulate through policies that require society control over education programming, transparency of industry funding for programming and publications, disclosure or recusal by faculty and guideline authors, and overall prevention from overreliance on industry funding for operations. Evidence of AAN enforcement of such policies is AAN's 2011 reaccreditation with commendation by the ACCME_-demonstrating AAN's compliance with ACCME's criteria. In addition, AAN support from industry was well below that recommended by Rothman et al.: 18\% in 2009 and $17 \%$ in 2010 (including journal advertising revenues and meeting exhibits - both excluded from the calculations recommended by Rothman et al.). ${ }^{6}$

The AAN considers its development and distribution of clinical practice guidelines as one of the most crucial services provided by the AAN to its membership and the public - a sentiment shared by Rothman and colleagues ${ }^{1}$ with regards to PMAs and guidelines generally. Rothman et al. ${ }^{1}$ concluded that PMAs should not accept funding from industry to develop guidelines. The AAN (and CMSS) agrees. The Principles expressly prohibit the AAN from accepting industry funding for development and initial distribution of guidelines. ${ }^{4}$ Rothman et al. ${ }^{1}$ further recommended that, in time, PMAs only select guideline development committee and panel members who are free of ties to industry. The AAN has considered COI with regards to guideline committee and panel members at length ${ }^{8}$ — at present, the AAN concludes that requiring disclosure of relationships with industry, prohibiting the number of members with such relationships, requiring abstentions from writing or voting when significant COI are identified (addressed on a case-by-case basis in accordance with the Policy on Conflicts of Interest), and posting disclosures appropriately protect the integrity of clinical practice guidelines. Since adoption of the CMSS Code, the AAN requires a majority of the guideline development panel members to be free of COI relevant to the subject matter of the guideline. In addition, the chair of the panel (or at least one of the chairs, if multiple) is required to be free of COI. The AAN is currently updating its guideline process documentation to reflect these changes (which have been implemented in practice) and recent adoption of the IOM Standards for Systematic Reviews. ${ }^{9}$ The AAN continually evaluates its COI regulation with regards to guideline development to determine whether Rothman and colleagues' proposal of having no development committee/panel members with relationships with industry is necessary to protect guidelines from inappropriate industry influence.

Since 2008, the AMA has pursued a renewed attempt to develop a broad policy on physician and PMA COI. Unable to reach consensus in 2009, the AMA limited its focus to COI in CME. During the 2010 meeting of the AMA House of Delegates the issue was referred back to the Council on Ethical and Judicial Affairs (CEJA) for its consideration. In 2011, CEJA released Report 1-A-11, "Financial Relationships with Industry in Continuing Medical Education." 10 AAN policy and practices are congruent with the principles identified in the report: minimizing industry influence on programming, transparency for learners, firewalls between industry and program development. Having zero industry involvement with CME programming is a sound aspirational goal, as noted by CEJA. However, having industry support does not present a prima facie unethical situation and the integrity of the AAN can be protected with appropriate measures (as outlined in the Principles, CEJA report, and ACCME Standards).

OTHER INTERESTING CONFLICTS Although potential COI are inherent in contemporary professional life, regulatory attention to them has been selective. The most highly publicized COI involve physicians receiving payments from industry for various services. However, other COI in medical practice include financial incentives for physicians in fee-for-service reimbursement systems to provide unnecessary medical services ("overcare") and the opposite financial incentives for physicians in prepaid reimbursement systems to fail to provide necessary medical services ("undercare"). In academic life, au- 
thors' disclosure of industrial support is vigorously enforced for journal articles but not for textbook chapters which students and residents study. However, we note that despite rigorous standards for authors' disclosures of conflicts of interest on the part of journals such as Neurology, ${ }^{11} \mathrm{JAMA},{ }^{12}$ and most others, such standards are no guarantee of author compliance with COI policy. ${ }^{11}$ Indeed, a recent article reported on data from pharmaceutical industry records of payments that $40 \%$ of one specialty's authors did not disclose their conflicts. ${ }^{13}$ Finally, pharmaceutical advertising directly to the public (including magazines, newspapers, and other venues), a practice permitted in the United States, has garnered little attention despite the potential effects on influencing patient requests and physician prescribing habits. ${ }^{14}$

CONCLUSION The work of the AAN task force and the subsequent revisions to the Principles Governing Academy Relationships with External Sources of Support, which focused on the AAN's relationships with industry, further emphasize the AAN's commitment to addressing COI with adoption of strict requirements for avoidance, separation, disclosure, and regulation.

\section{COINVESTIGATORS}

The American Academy of Neurology Pharmaceutical and Device Industry Conflict of Interest Task Force: James Bernat, MD, FAAN (Chair), Dartmouth-Hitchcock Medical Center; Thomas Swift, MD, FAAN, Medical College of Georgia; Bernard Ravina, MD, FAAN, University of Rochester; Dan Larriviere, MD, JD, Ochsner Medical Center; Timothy Pedley, MD, FAAN, the Neurological Institute of New York; Corey Fehnel, MD, Massachusetts General Hospital; Murray Sagsveen, JD, CAE, American Academy of Neurology; Christine Phelps, American Academy of Neurology; Rod Larson, American Academy of Neurology; John C. Hutchins, JD, American Academy of Neurology-Staff Liaison.

\section{AUTHOR CONTRIBUTIONS}

J.C. Hutchins: drafting/revising the manuscript. C.M. Rydell: drafting/ revising the manuscript, study concept or design, analysis or interpretation of data, acquisition of data. Dr. Griggs: drafting/revising the manuscript. Murray Sagsveen: drafting/revising the manuscript. Dr. Bernat: drafting/revising the manuscript, study concept or design.

\section{DISCLOSURE}

J.C. Hutchins is currently the Associate General Counsel of the American Academy of Neurology and General Counsel of the American Academy of Neurology Foundation. C. Rydell is currently the Executive Director of the American Academy of Neurology and the American Academy of Neurology Foundation and the Chief Executive Officer of AAN Enterprises, Inc. Dr. Griggs holds NIH funding for a multicenter clinical trial of corticosteroids in Duchenne Muscular Dystrophy, for a multicenter clinical trial of dichlorphenamide in periodic paralysis, and for a Rare Disease Clinical Research Center Consortium for the neurologic channelopathies; he served as a consultant for PTC Therapeutics (as Chair of the DSMB for a study of PTC 124 in DMD); his institution receives support from Taro Pharmaceuticals for a clinical trial in periodic paralysis; he is Chair of the Executive Committee of the Muscle Study Group which receives support from pharmaceutical companies, from the NIH, and from the US FDA (he does not receive personal compensation from any of the foregoing entities or grants); he also served as President of the American Academy of Neurology, 2009-2011. M. Sagsveen reports that, at the time he contributed to the manuscript, he was General Counsel of the American Academy of Neurology. Dr. Bernat serves on the editorial boards of Multiple Sclerosis and Related Disorders; Neurocritical Care; Neurology Today; and The Physician's Index for Ethics in Medicine.

Received June 14, 2011. Accepted in final form October 26, 2011.

\section{REFERENCES}

1. Rothman DJ, McDonald WJ, Berkowitz CD, et al. Professional medical associations and their relationships with industry: a proposal for controlling conflict of interest. JAMA 2009;301:1367-1372.

2. Council of Medical Specialty Societies. Code for Interactions with Companies, March 2011. Available at: http:// www.cmss.org/codeforinteractions.aspx. Accessed September 7, 2011.

3. Council of Medical Specialty Societies. Signatories of the Code for Interactions with Companies. Available at: http://www.cmss.org/OriginalSigners.aspx. Accessed January 20, 2012.

4. American Academy of Neurology. Principles Governing Academy Relationships with External Sources of Support (2011). Available at: http://www.aan.com/go/about/ethics. Accessed September 7, 2011.

5. American Academy of Neurology. Policy on Conflicts of Interest (2010). Available at: http://www.aan.com/go/ about/ethics. Accessed September 7, 2011.

6. American Academy of Neurology. Organizational Disclosure (2011). Available at: http://www.aan.com/go/ membership/disclosure. Accessed September 21, 2011.

7. American Academy of Neurology. Board Disclosure (2011). Available at: http://www.aan.com/go/about/ board/disclosures. Accessed September 21, 2011.

8. Holloway RG, Mooney CJ, Getchius TSD, et al. Invited article: Conflicts of interest for authors of AAN clinical practice guidelines. Neurology 2008;71:57.

9. Institute of Medicine. Standards for Systematic Reviews, March 23, 2011. Available at: http://www.iom.edu/Reports/ 2011/Finding-What-Works-in-Health-Care-Standards-forSystematic-Reviews/Standards.aspx?page $=4$. Accessed September 21, 2011.

10. American Medical Association. Council on Ethical and Judicial Affairs, Report 1-A-11, "Financial Relationships with Industry in Continuing Medical Education” (2011). Available at: http://www.ama-assn.org/resources/doc/ ethics/ceja-1a11.pdf. Accessed June 20, 2011.

11. Gross RA, Knopman DS. Reporting potential bias: Neurology's evolving policies. Neurology 2011;76:110-112.

12. Fontanarosa PB, Flanagin A, DeAngelis CD. Implementation of the ICMJE form for reporting potential conflicts of interest. JAMA 2010;304:1496.

13. Chimonas S, Frosch Z, Rothman DJ. From disclosure to transparency: the use of company payment data. Arch Intern Med 2011;171:81-86.

14. Kravitz RL, Epstein RM, Feldman MD, et al. Influence of patients' requests for direct-to-consumer advertised antidepressants: a randomized controlled trial. JAMA 2005;293: 1995-2002. 


\section{Neurology}

\section{American Academy of Neurology policy on pharmaceutical and device industry support}

J.C. Hutchins, C.M. Rydell, R.C. Griggs, et al.

Neurology 2012;78;750-754

DOI 10.1212/WNL.0b013e318248e4ff

\section{This information is current as of March 5, 2012}

\section{Updated Information \&} Services

Supplementary Material

\section{References}

Citations

Subspecialty Collections

Permissions \& Licensing

\section{Reprints}

including high resolution figures, can be found at: http://n.neurology.org/content/78/10/750.full

Supplementary material can be found at: http://n.neurology.org/content/suppl/2012/03/04/78.10.750.DC1 http://n.neurology.org/content/suppl/2012/03/04/78.10.750.DC2

This article cites 6 articles, 2 of which you can access for free at: http://n.neurology.org/content/78/10/750.full\#ref-list-1

This article has been cited by 2 HighWire-hosted articles: http://n.neurology.org/content/78/10/750.full\#\#otherarticles

This article, along with others on similar topics, appears in the following collection(s):

All Ethics in Neurology/Legal issues http://n.neurology.org/cgi/collection/all_ethics_in_neurology_legal_iss ues

Information about reproducing this article in parts (figures,tables) or in its entirety can be found online at:

http://www.neurology.org/about/about_the_journal\#permissions

Information about ordering reprints can be found online: http://n.neurology.org/subscribers/advertise

Neurology ${ }^{\circledR}$ is the official journal of the American Academy of Neurology. Published continuously since 1951 , it is now a weekly with 48 issues per year. Copyright Copyright $@ 2012$ by AAN Enterprises, Inc.. All rights reserved. Print ISSN: 0028-3878. Online ISSN: 1526-632X.

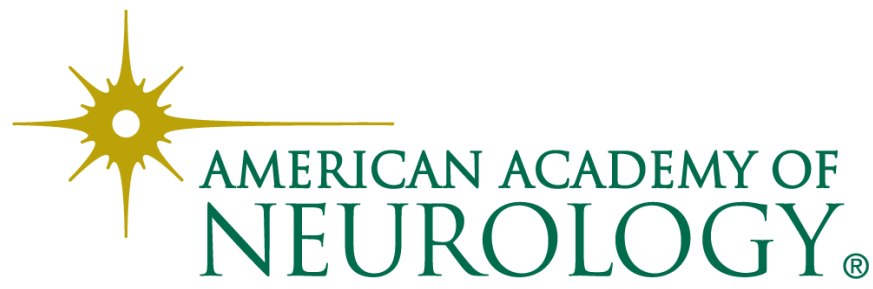

